\title{
Medios de comunicación y neoliberalismo en Argentina
}

\author{
Media and neoliberalism in Argentina
}

Juan Luis Francia

(Lycée Polyvalent du Cheylard, Auvergne-Rhône-Alpes)

\begin{abstract}
Resumen: En este trabajo se utiliza una muestra de noticias desde 2015 a 2019 procedentes de tres de los principales periódicos argentinos y de algunos medios de comunicación digitales del mismo país para desarrollar una reflexión sobre la relación entre mass media y poder. Los resultados sugieren que la prensa es un brazo de las políticas de lawfare aplicadas en Argentina al servicio de implementar políticas neoliberales y en desmedro del régimen democrático. La oposición política y los llamados líderes populistas han sido sistemáticamente descalificados, ridiculizados y calumniados. Mientras, con un poderoso ariete comunicacional se logró instalar en la presidencia de Argentina en el año 2015 a Mauricio Macri, un personaje con una carrera política breve y numerosos escándalos en su historial que lo vinculaban con el contrabando, las escuchas ilegales y la corrupción.
\end{abstract}

Palabras clave: medios de comunicación; neoliberalismo; propaganda; lawfare.

\begin{abstract}
In this work, we use a sample of news from 2015 to 2019 from three of the main Argentinian newspapers and some digital media in the same country. This is used to develop a reflection about the relation between mass media and power. The results suggest that the press is an arm of the lawfare policies applied in Argentina in order to implement neoliberal policies and to the detriment of the democratic regime. The political opposition and the so-called populist leaders have been systematically disqualified, ridiculed and slandered. Meanwhile, with a powerful communication battering ram, Mauricio Macri was installed in Argentina's presidency in 2015, a character with a brief political career and numerous scandals in his record that linked him to smuggling, illegal recordings and corruption.
\end{abstract}

Keywords: media; neoliberalism; propaganda; lawfare 
Si yo miento en un pleito sobre la suerte de la vaca de mi vecino puedo ir a la cárcel. En cambio si miento a un millón de personas en un tema que afecta a la guerra o a la paz, puedo decir lo que me plazca y, si elijo la serie adecuada de mentiras, resultar sin responsabilidad alguna [Walter Lippmann (1919). Qué significa la libertad moderna. The Atlantic Monthly].

\section{Antecedentes históricos}

En tiempos de la revolución de mayo de 1810, se instala en Buenos Aires la primera junta de gobierno patrio. Este gobierno no declara la independencia de la corona española, más bien aprovecha la circunstancia de que Fernando VII, rey por entonces de España, era un cautivo de Napoleón Bonaparte, quien había instalado en el trono español a su hermano José. Esta circunstancia fue usada por los patriotas argentinos, quienes manifestaban la pretensión de "sostener con dignidad los derechos del rey" quien, desde su cautiverio, había dejado acéfalo el reino.

Mariano Moreno, fue el promotor y editor de la Gazeta de Buenos Ayres, primer medio de prensa argentino. El periódico semanal fue creado por la junta provisoria de gobierno para combatir por un lado los rumores y conspiraciones y, por otro lado, dar a conocer la acción de gobierno. Además de estas necesarias tareas debía cumplir una función propagandística tal como Mariano Moreno revela en el plan secreto de gobierno.

Mariano Moreno y el gobierno del que formaba parte utilizaron el nombre del rey para conseguir apoyos externos e internos a la revolución. De tal manera comprobamos que hubo una manipulación de la información con los fines de consolidar la independencia.

Esto nos plantea un dilema, ¿es criticable la manipulación sólo cuándo viene desde el establishment, de los poderes consolidados, de los grupos concentrados del poder económico? Si los fines de la manipulación son alcanzar la libertad y la igualdad, ¿atenúan el juicio ético sobre la misma? Es decir ijustifica el fin loable o revolucionario la manipulación y la propaganda aplicada desde los medios de comunicación de masas y desde otras vías? ¿Sólo es reprochable la manipulación mediática si el objetivo de la misma es la construcción o consolidación de un orden injusto, excluyente y antidemocrático?

Lo cierto es que la concentración de medios comunicación de masas en muy pocas manos hace a estos interrogantes inútiles en el mundo actual.

Y el uso de las redes sociales como quinto poder que le atribuyen algunos, tiene el defecto que su control y vigilancia total de las comunicaciones por quienes controlan Internet permite la represión selectiva. Julian Assange recuerda el caso de "El Cairo [donde] se organizó en 2008 una protesta a través de Facebook. Ésta tomó por sorpresa al Gobierno de Mubarak y, en consecuencia, estas personas fueron identificadas luego a través de Facebook", algunas de esas personas fueron torturadas para extraerles sus contraseñas. 


\section{Neoliberalismo y propaganda}

El neoliberalismo, según los filósofos franceses Pierre Dardot y Christian Laval, es una doctrina que va más allá de lo económico, y que busca implementar una lógica de mercado en todos los ámbitos de la vida. No es un programa económico, sino que se trata de algo mucho más ambicioso que eso, "la economía es el método, el objetivo es cambiar el alma", decía la primera ministra británica Margaret Thatcher, pionera en políticas neoliberales en Europa.

En Argentina, el neoliberalismo desembarcó en el año 1976, con la dictadura cívico militar de la que el principal periódico argentino, Clarín, fue un activo socio. Los beneficios de esta complicidad obtenidos por el grupo empresarial de prensa se pudieron apreciar en su crecimiento patrimonial y de su influencia ganada en el terreno de la comunicación.

Estas políticas neoliberales que perjudican a las mayorías porque se basan en el traspaso de riqueza de los que menos tienen a los que más tienen, requieren de represión y de persuasión. Al comenzar la última dictadura argentina en 1976 los trabajadores participaban del 43\% del Producto Interior Bruto. Poco antes de culminar el gobierno dictatorial, en 1982, el porcentaje del PIB destinado a los asalariados había bajado al $22 \%$.

Luego de esta experiencia neoliberal en Argentina se cambió de estrategia; la tortura y desaparición de personas dejó lugar a la persuasión. Así, con intensas campañas propagandísticas se preparó el terreno para desembarcar por segunda vez con estas políticas en los años 90, que culminaron con el estallido social de 2001.

El tercer capítulo de neoliberalismo argentino, que parece nunca terminar de morir pese a su fracaso estrepitoso, vino de la mano de Mauricio Macri.

En el triunfo electoral de Macri en 2015 y su acceso a la presidencia de la República tuvo un papel fundamental una campaña propagandística y de manipulación de la opinión pública inédita en Argentina, liderada por el grupo Clarín. El grupo monopólico de medios de comunicación en Argentina logró influir sobre la opinión pública de manera decisiva, y consolidar sus privilegios y los de sus socios, razón última por la que se empleó a fondo para colocar a Mauricio Macri en la presidencia de la nación. Durante años, el multimedios propagó mentiras e imputaciones falsas al gobierno kirchnerista y sus integrantes, así fue preparando el ambiente para inclinar la balanza y cambiar el gobierno.

Julio Blanck, editor de Clarín, reconoció en una entrevista que habían hecho "periodismo de guerra" contra el kirchnerismo, que fueron "buenos haciendo guerra, pero que en realidad eso no era periodismo".2

Walter Lippmann ya en 1919 denostaba estas prácticas periodísticas al decir que "la más destructiva forma de falsedad es la sofistería y la propaganda a cargo de aquellos cuya profesión es comunicar las noticias".

\footnotetext{
${ }^{1}$ Dardot, P. y Laval, C. (2016). Ce cauchemar qui n'en finit pas. Comment le néolibéralisme défait la démocratie. París: La Découverte. https://www.eldiario.es/interferencias/neoliberalismo-ideologia-politica-economicaforma_6_312228808.html https://www.perfil.com/noticias/medios/julio-black-periodismo-de-guerra-clarin-kirchnerismo-cambiemosideas.phtml (visita el 5/12/2019).
} 
Entendemos como propaganda a una campaña sistemática que se propone persuadir o "influenciar en la opinión o acción de individuos o grupos (...) mediante manipulaciones psicológicas" como dice Harold Laswell (citado en Ramonet, 2007). En este sentido, es muy gráfico el ejemplo que da Noam Chomsky sobre el funcionamiento de la Comisión Creel creada por el gobierno de Estados Unidos en 1917. La mencionada comisión desarrolló una campaña de propaganda tan abrumadora en el país, que al cabo de seis meses había logrado el objetivo de convertir una población pacifista, en una belicista y favorable a intervenir en la Primera Guerra Mundial.

\section{Clarín-Macri, matrimonio de conveniencia}

Durante la dictadura cívico-militar que gobernó Argentina, entre 1976 y 1983, asesinando a miles de compatriotas con la impunidad que otorgan el control del Estado y de los medios de comunicación, se dictó un decreto-ley que reguló la radiodifusión en el país. Este decreto-ley de radiodifusión continuó vigente durante los gobiernos democráticos que le sucedieron, hasta octubre de 2009, cuando promovido por el gobierno de Fernández de Kirchner, el congreso logró sancionar la Ley de Servicios de Comunicación Audiovisuales de Argentina número 26.522. Dicha ley tenía dos ejes, según señalaba el periodista argentino Néstor Piccone, "la desmonopolización y la promoción de la multiplicidad de voces".

Los debates previos a la sanción de la Ley de medios, contaron con la participación de diferentes organizaciones e instituciones de la sociedad y que culminaron con el debate parlamentario y la sanción de la ley. Este mecanismo participativo hizo de esta norma la más democrática de todas las elaboradas por el Poder Legislativo argentino. Luego de sancionada la Ley de medios, ésta establecía un año de plazo para que los grupos empresariales se adaptaran a la nueva legislación, pero Clarín continuó su resistencia protegido por una red de jueces que a través de medidas cautelares congelaban la aplicación de la ley al grupo, que logró evitar así desprenderse de sus múltiples medios de comunicación.

Al llegar a la presidencia Mauricio Macri en 2015 una de sus primeras medidas fue desarticular la Ley de medios vía decreto del Poder Ejecutivo. El decreto eliminó los artículos antimonopólicos que tanto disgusto generaron a Clarín, y suprimió también el organismo encargado de velar por el cumplimiento de la ley, la Autoridad Federal de Servicios de Comunicación Audiovisual (AFSCA). De esta manera, Macri realizaba un primer "pago" al grupo multimedios por su rol protagónico en la campaña antikirchnerista que le permitió a Macri alcanzar la presidencia en segunda vuelta, por tan sólo 2,9\% de diferencia sobre el candidato oficialista, Daniel Scioli.

Pero después de eso el rol bélico, Clarín no se detuvo y su "guerra" contra el kirchnerismo continuó, había que erradicar el cáncer para que este no se volviese a reproducir.

El grupo Clarín también hizo uso de la censura para blindar a Macri, de lo que abundan ejemplos: el silencio que guardó el monopolio sobre la información filtrada por el portal Wikileaks, que reveló que Mauricio Macri había reclamado en varias oportunidades a funcionarios de la embajada de Estados Unidos en Buenos Aires que el gobierno del norte fuera más duro con los Kirchner, que debía reprocharles públicamente sus políticas; en síntesis, le pedía que asumiera un papel más activo en sus injerencias sobre Argentina. Otro caso más 
evidente aún de censura y complicidad de Clarín con Macri fue el escándalo de los Panamá Papers que involucró directamente al presidente, y que provocó renuncias de numerosos políticos en el mundo entero pero que en Argentina fueron cuidadosamente dejadas de lado de la agenda informativa del grupo Clarín, que continuó brindando protección mediática a la figura política de Macri durante los cuatro años de su gobierno.

Mauricio Macri, presidente y empresario multimillonario, llevó adelante políticas acordes a sus intereses de clase que se tradujeron en un aumento considerable de tarifas de servicios públicos en beneficio de los prestadores privados (algunos de ellos ministros y amigos personales del presidente), aumento generalizado de los precios de bienes de consumo popular, disminución del presupuesto destinado a la salud, cultura y educación. La reducción considerable de los impuestos a los sectores agroexportadores y la eliminación de las retenciones a empresas mineras y otras multinacionales, que fueron acompañados de una exigencia de Macri a los trabajadores para que hicieran sacrificios por el país y no pidieran aumentos salariales que mitigaran la pérdida de su poder adquisitivo.

El presidente Macri ha llegado a declarar que en el Estado argentino sobraban un millón y medio de empleados y despidió un buen número de ellos, contando como siempre con el silencio de los medios de comunicación, y promovió el despido de los periodistas críticos al gobierno. Así perdieron sus trabajos el periodista Roberto Navarro, que denunciaba la política económica "para pocos" del macrismo en el canal de noticias C5N. El dueño del canal de televisión, Cristóbal López, reconoció más tarde que lo despidió para evitar ir a la cárcel con la que lo amenazaba el gobierno, finalmente no le alcanzó cumplir con esta indigna tarea y fue a prisión de todas maneras. Víctor Hugo Morales, uno de los periodistas más críticos con Macri y Clarín, fue despedido de Radio Continental. Horacio Verbitsky, periodista también muy crítico con el gobierno de Macri tuvo que marcharse del diario Página 12 para el cual trabajaba. La larga lista de periodistas despedidos por su posición política revela que la libertad de expresión era considerada como un obstáculo por el gobierno para alcanzar sus metas prefijadas. La censura del régimen apuntaba a consolidar el discurso hegemónico eliminando todas las voces críticas y alternativas.

\section{Lawfare $^{3}$}

Los cuatro años del "Leviatán macrista" trajeron la novedad a la Argentina de los presos políticos en democracia. Uno de los casos más emblemático es el de Milagro Sala, una lideresa popular presa desde diciembre de 2015 por protestar y acusada formalmente de corrupción y otros delitos. Mientras tanto han pedido por su liberación el Vaticano, la Comisión Interamericana de Derechos Humanos (CIDH), Amnistía Internacional, el premio Nobel de la Paz Adolfo Pérez Esquivel, Noam Chomsky y el Centro de Estudios Legales y Sociales (CELS) entre otros. Todo fue en vano.

Pero la lista de presos políticos también es larga: jueces y fiscales cómplices del gobierno se dedicaron a meter en "prisión preventiva" líderes políticos, sindicales y sociales en todo el país, con diferentes excusas y vulnerando el Estado de Derecho. En casi todos los casos se trata de

\footnotetext{
${ }^{3}$ https://www.youtube.com/watch?time continue=18\&v=_chJuEnEmyw\&feature=emb_logo (visita el 5/12/2019).
} 
presos sin condena, ignorando el principio jurídico de inocencia hasta que se demuestre lo contrario.

Este trabajo de extorsión y cacería de opositores rebeldes contó con la aceitada maquinaria de Clarín y otros medios aliados como La Nación, que se dedicaron a socavar la imagen de líderes políticos y sociales como paso previo al procesamiento judicial.

Pero a nadie escapa que el mayor objetivo, fallido hasta el momento, era meter presa a Cristina Fernández de Kirchner. La líder política con mayor apoyo popular ya había denunciado en su discurso en el Senado de la nación en diciembre de 2017, que era víctima de una guerra jurídica y mediática. La misma Cristina se encargaría de popularizar en el lenguaje político argentino el concepto de lawfare:

La verdad es que esta utilización del Poder Judicial para perseguir, estigmatizar y desprestigiar a los dirigentes no es un atributo argentino. No somos originales ni novedosos en esto. El lawfare, término acuñado en los Estados Unidos y desarrollado en la Universidad de Harvard, habla de la utilización del aparato judicial, en una articulación con los medios de comunicación, para provocar condenas previas sin juicio a dirigentes políticos de la oposición. Hay numerosos ejemplos que están sucediendo en toda la región latinoamericana. Es un modus operandi, una matriz latinoamericana (Fernández de Kirchner, sesión extraordinaria del senado de la nación, 2017, p. 7). ${ }^{4}$

Pero Cristina Fernández, gracias a la inconsistencia de las acusaciones y a su estrategia electoral de colocarse en el último momento como candidata a vicepresidenta, hecho que desorientó a propios y extraños, estropeó el plan de sus enemigos. La senadora convocó a Alberto Fernández, un antiguo jefe de gabinete de su gobierno, a integrar la fórmula como candidato a presidente. De esta forma Cristina logró derrotar al frente oligopólico mediático empresarial encabezado por Mauricio Macri que pretendía inhabilitarla políticamente y encarcelarla, para dejar sin alternativa electoral a las clases populares como había ocurrido con Lula en Brasil.

Para confirmar la falta de originalidad argentina en la utilización de la justicia como arma para perseguir opositores, el político francés Jean-Luc Mélenchon, revela que el lawfare ha llegado también a Francia y que él lo sufre en persona. Mélenchon define el lawfare en términos similares a los de Cristina: "une instrumentalisation délibérée de la justice et de la police par le pouvoir pour atteindre un but d'elimination politique d'un adversaire". ${ }^{5}$

El lawfare de aplicación simultánea en toda la región latinoamericana, aunque más sutil, recuerda a otros programas de alcance continental como el Plan Cóndor, que coordinó a las dictaduras militares latinoamericanas durante los años 70 y 80 para perseguir a los disidentes políticos más allá de las fronteras nacionales.

Por otra parte, cuando el lawfare no funciona, la alternativa de recurrir al viejo manual del golpe de Estado clásico, con tanques en las calles, asesinatos, torturas, desaparecidos y proscripción

\footnotetext{
${ }^{4}$ https://www.clarin.com/politica/lawfare-palabra-uso-cristina-criticar-justicia-primer-discurso-senado-2017 0 _HycRr-Qz.html y https://www.argentina.gob.ar/sites/default/files/cs_vt_sesion_senado.pdf (visitas el 5/12/2019).

${ }^{5} \mathrm{La}$ instrumentalización deliberada de la justicia y la policía por el poder, con el fin de eliminar a un adversario político.
} 
política no está para nada descartada, tal como demuestra el caso de Bolivia. Las élites regionales y Washington no renuncian a ninguno de sus métodos con tal de conseguir el resultado deseado: recuperar el control perdido en la región.

En este último sentido y volviendo a Argentina, es preocupante que, frente al golpe de Estado de Bolivia, el gobierno de Mauricio Macri se haya negado a calificarlo como tal. Macri y su alianza política conservadora pasan a integrar desde el 10 de diciembre de 2019 la oposición, y desde esa misma lógica podrían avalar un golpe de Estado en Argentina, y considerarlo simplemente como un mero cambio de gobierno. Ni la democracia ni los Derechos Humanos han sido considerados como valores a defender por parte del gobierno Macri, y el caso boliviano es una prueba más de ello.

\section{Conclusión}

La Argentina del cuatrienio neoliberal de Mauricio Macri deja como saldo en materia democrática una degradación del sistema por los ataques a la libertad de expresión y al Estado de Derecho.

Los líderes políticos, sociales y sindicales que se encuentran perseguidos o encarcelados por el régimen macrista, tienen algo en común, además de ser opositores, son críticos de las políticas neoliberales. En general podríamos resumir que las víctimas del lawfare en Argentina están a favor de un rol más activo del Estado en la economía con el objeto de favorecer los estamentos más vulnerables de la sociedad.

Pero como señalábamos más arriba, la guerra jurídica contra quienes resisten el neoliberalismo no se da sólo en Argentina, también lo vemos en otras latitudes. Todas las víctimas del lawfare comparten en líneas generales una visión ideológica de vivir en una sociedad con mayor libertad, justicia social e igualdad.

En síntesis, podríamos reconocer que se trata de personas que encarnan algunos de los viejos valores consagrados en la Revolución Francesa: Liberté, Égalité et Fraternité. Esto último, por oposición, nos pudiera dar una medida de adónde nos conducen los Macri, Piñera, Bolsonaro o Macron: a una sociedad que elimine los valores consagrados por la democracia moderna y dónde sólo existan derechos para quienes se los puedan pagar.

\section{Referencias bibliográficas}

Assange, J., Appelbaum, J., Müller-Maguhn, A. y Zimmermann, J. (2012). Criptopunks. La libertad y el futuro de internet. Buenos Aires: Marea.

Beleño, A. (2016). Periodismo y Guerra. Caracas: Trinchera.

Bernays, E. (2008). Propaganda. Barcelona: Melusina.

Boron, A. (2013). América Latina en la geopolítica del imperialismo. Caracas: Ministerio del Poder Popular para la Cultura.

Bourdieu, P. (1998). "La esencia del neoliberalismo", Le Monde Diplomatique, marzo.

Calloni, S. (2016). Operación Cóndor, pacto criminal. Caracas: El perro y la rana. 
Chomsky, N. y Herman, E.S. (2014). Los guardianes de la libertad. Barcelona: Austral.

Chomsky, N. y Ramonet, I. (2002). Cómo nos venden la moto. Barcelona: Icaria.

Chomsky, N. (2000). Sobre el Poder y la ideología. Madrid: Visor Vis.

Chomsky, N. (2007). Ilusiones necesarias. La Plata: Terramar.

Fernández Savater, A., Malo, M. y Ávila, D. (2014). "Laval y Dardot: El neoliberalismo es una forma de vida, no sólo una ideología o una política económica”, eldiario.es, 10 de octubre.

Gago, V. (2015). La razón neoliberal. Buenos Aires: Traficantes de Sueños.

García Marín, J. (2011). "Encuadres, conflictos y efectos de agenda", Zer-Revista de Estudios de Comunicación, 16(31), 167-181.

Moreno, M. (2006). Plan Revolucionario de Operaciones. Buenos Aires: Lancelot.

Mélenchon, J.-L. (2019). Et ainsi de suite. Un procès politique en France. París: Plon.

Lippmann, W. (2011). Libertad y prensa. Madrid: Tecnos.

Piccone, N. (2015). La inconclusa ley de medios. La historia menos contada. Buenos Aires: Continente.

Pineda, A. (2001). "El modelo de Propaganda de Noam Chomsky: medios mainstream y control de pensamiento", Ámbitos-Revista Latina de Comunicación Social, 6.

Ramonet, I. (2007). Propagandas silenciosas. Caracas: El perro y la Rana.

Serrano, A. (2015). América Latina en Disputa. Caracas: El perro y la Rana.

Toussaint, E. (2014). Una Mirada al Retrovisor. El neoliberalismo desde sus orígenes hasta la actualidad. Caracas: Centro Internacional Miranda.

\section{Otros recursos:}

http://www.pagina12.com.ar/diario/suplementos/cash/48-8910-2015-11-06.html http://www.comisionporlamemoria.org/archivos/educacion/memoria-en-las-aulas/dossier13.pdf http://www.elcato.org/sites/default/files/camino-de-servidumbre-libro-electronico.pdf http://santiagoodonnell.blogspot.fr/search?q=macri+embajada 